\title{
Supporting Remote Laboratory Activities at an Institutional Level
}

\author{
http://dx.doi.org/10.3991/ijoe.v9iS5.2772 \\ Alexander A. Kist, Peter Gibbings, Andrew D. Maxwell, Hannah Jolly \\ University of Southern Queensland, Toowoomba, Australia
}

\begin{abstract}
Learning Tools that rely on information and communication technologies form an essential part of distance education. Remote Access Laboratories (RAL) is one example that has been widely discussed in the research community; in particular, in the context of engineering and science education. However, remote laboratory technology is not widely used. This study explores whether the benefits offered by the RAL systems can be extended to students in other disciplines and how this process can be supported. The key aim of this activity is to create more equitable opportunities for student learning across faculties and the university. The study identifies considerations for the wider adoption, implementation and uptake of remote laboratory based learning activities. Four learning activities at various stages of the development cycle in three different disciplines are evaluated using a program logic methodology. Evaluation questions address the areas of appropriateness, effectiveness, efficiency, impact and sustainability. It is concluded that remote laboratory are open and flexible enough to suite a variety of learning objectives and pedagogies in a number of contexts. This study also highlights some wider issues that are significant to the acceptance of RAL learning activities. Findings include that a number of conditions need to be met if remote laboratory activities are to occur more broadly across universities as learning systems.
\end{abstract}

Index Terms-Remote Access Laboratory, Remote Laboratory, practical learning activities, learning system.

\section{INTRODUCTION}

For almost two decades, Remote Laboratories (RL) or Remote Access Laboratories (RAL) have been discussed by the academic community as means to address access issues to hardware and laboratory spaces, limited utilisation of hardware [1] and to support distance education [2]. Besides the wide range of individual learning activities and hardware installations (rigs) [3, 4], there are also a number of large scale initiative that seek to provide wider, coordinated approaches to integrating RAL technology and pedagogies into higher education curricula; for example, the iLab [5] and LabShare [6] projects. The motivation for originators to develop RAL technology differs but broadly fall into two categories: to enable more engagement opportunities for students and financial consideration such as increasing utilisation of (expensive) equipment.

Besides this active research and development community, RAL technology is not as prevalent as other electronic learning tools such as Course Management Systems (CMS), for example.

This study seeks to explore some of the reasons that contribute to this situation and to identify considerations for the wider implementation, uptake and embedding of RL learning activities across universities. To achieve this, this study explores whether and how the benefits offered by RL based learning activities can be extended to students in other disciplines and faculties.

The Faculty of Engineering and Surveying (FoES) at the University of Southern Queensland (USQ) has develop a RAL system with a strong focus on the access issues surrounding practical laboratory learning activities. The institution is a distance education provider with approximately 76 per cent of students studying externally. In addition to projects that have focus on the overall RAL system as well as individual rigs and learning activities in the FoES, a study has been undertaken with aim to explore whether benefits that are offered by RL systems can be extended to students in other disciplines; and how this could be achieved; the main aim being to provide more equitable learning opportunities across the institution.

Using a Program Logic model [7] a number of evaluation questions were formulated in the areas of appropriateness, effectiveness, efficiency, impact and sustainability. Key initiatives in engineering, education and nursing were evaluated during the process of developing, implementing and trailing RAL-based learning activities. Through this process the project has identified considerations for the wider implementation, embedding and uptake of RAL as an online learning tool across the institution.

This paper extends a summary of these results that were initially reported in [8]. The research question providing focus for this study was: What are necessary conditions to move from individual RAL implementations to institutional learning tools?

The main conditions can be summarised as follows:

a RAL system that is easy to use and ideally integrated with the learning management system [2];

an extended concept of RAL from hardware rigs to conceptual spaces [9];

engaging other disciplines with the ideas of RAL (Section III);

aligning efforts with institutional goals (Section IV).

The study outlines how other disciplines can be engaged in developing novel RAL learning activities and confirms that it is important that educational project align with the institutions strategic goals. The driving aim for this study was to evaluate the necessary institutional and learning conditions (or barriers) influencing the uptake of RAL learning systems and activities; and to evaluate how technology-driven learning activities can be migrates from nice applications in disciplines to universal learning tool for institutions. 
The reminder of this paper is organised as follows: Section II addresses the theoretical framework that underpins this research project and Section III discusses the learning activities that were investigated. Section IV introduces the institutional background and how it relates to this research project and Section V highlights the methodology that was employed during this study. The results are discussed in Section VI and findings are summarised in Section VII. Implications of this study and the path forward are summarised in Section VIII. The paper concludes with Section IX.

\section{EDUCATIONAL FRAMEWORK}

Experimentation plays an important role in engineering curricula and Remote Access Laboratories have been widely advocated as educational activities. Usually RALs are seen a tools to provide access to hardware experiments and systems remotely. Kist et al. [9] have proposed to extend the concept to include remote experimentation in any form.

The reasoning behind the use of RALs include the ability to share hardware between physical locations within and between and institutions e.g. remotely controlled robots [10] or control laboratories [11]. It is also expected that sharing resources leads to economic benefits [1]. There are a number of initiatives that take a broader approach to experiment access and integration including the Australian Labshare project [6] and the MIT iLab project [5]. When evaluating RAL literature, predominant attention has been paid to the system implementation details of particular experiments. Whilst this is important for the realisation of the actual experiment, questions regarding pedagogy, or how learning objectives are constrained and realised are left wanting.

Remote access can fulfil many of the learning requirements and objectives for experimentation, and may be able to provide additional benefits, such as increased flexibility for access by students [12, 13]. A common deficiency with laboratory work and practical content within engineering and science curricular, is that the objectives for including and implementing them are often not explicitly addressed [14]. "While course goals are often specified, the literature shows a general dearth of well-written student learning objectives for laboratories" [pp. 124].

As a result of this deficiency, and because instructional objectives for laboratories are rarely specifically stated, the learning experience from these events is often difficult to validly measure. As "the pedagogical effectiveness of any educational activity is judged by whether or not the intended learning outcomes are achieved" $[15$, p. 8] it is difficult to evaluate the success of a RAL learning activity. Appropriate design and realisation of measurable outcomes must also be applied to RAL learning activities.

Pre-existing and accepted learning theories can be framed as a basis for evaluation of the learning value of RAL activities, particularly Hanson et al. [16] who conclude that well-designed RAL activities have the capacity to offer specific benefits flexibility in learning environment, access and approach to the learning task, collaboration with peers; and immediate feedback. The authors suggest that such affordances can promote deeper learning and better connection between theory and practice, greater student engagement through increased control of the experience, and increased inclusivity [16, p.165].

White [17] describes the basis of the 'laboratory' where learning can be considered as instances where learning experience 'episodes' are enacted. Specifically where "the [learner] took part or at least observed," with the result that the experience is "linked to propositions [about facts, concepts, ideas] so that those propositions in turn are remembered and understood" [pp. 765-766]. As a result, Laboratories can be defined as either a physical or conceptual (virtual) space where this learning event or experience takes place. Additionally, 'laboratory learning' can then defined as the understanding or conceptualisation of the knowledge created during this event, which links experimental 'propositions' to conceptual understanding and then application and utility.

Expanding on White's definition it is possible to extend the concept of a 'laboratory' towards non-science disciplines. Thus we suggest that a Remote Access Laboratory is constituted by any activity where the student participates in events that link conceptual understanding of relevant and related information, concepts, ideas and propositions through an online or Internet based remote interface [9]. Importantly, cognitive psychology demonstrates that the process of learning involves more than activity, but memory, thinking and reflection [18], and the linkage of concepts both existing and new to promote the learning process [19].

\section{IMPLEMENTATION OF LEARNING ACTIVITIES AND THEIR AIMS}

In order to demonstrate how the RAL framework can be utilised to direct specific learning outcomes, particular case studies can be examined that typify this enablement. This section introduces four particular RAL experiments that largely occurred during 2011. For each experimental activity, details are provided to highlight the nature of the laboratory learning, the implementation stage of the RAL activities, and the learning objectives that are associated with undertaking these activities. The aims associated with undertaking these implementations are summarised in Table 1. More specific details on the activities can be found in [20].

\section{A. Faculty of Engineering (Remote access to specialised software)}

Students studying spatial science remotely access specialised and expensive software to process and visualise data for Geographic Information Systems (GIS). These packages are ordinarily unavailable to students for local installation on their own computer. The student must acquire knowledge for two stages of this package; the first is to acquire knowledge of how to access the institution's learning management system (LMS); and the second is then to learn how to access a "virtual computer" on which to perform pre-set tasks.

During these activities, students have to form the necessary workflows in order to use the software and to manage the access and storage processes (for example the virtual computer environment does not retain student's data outputs from the GIS activities between sessions so they need to be stored separate to the remote virtual computer on persistent systems.) The teacher additionally provides resources to help in this regard. 
The nature of the laboratory learning in this instance is inquiry-based. Students relate the investigation to previous work, predict results and perform investigations.

At a student level the aims are to provide students with access to expensive and restricted software that they will typically need to be aware of in professional setting; and to reduce the need for students to attend on campus for residential school, or reduce time on task required to satisfy the particular activity goals.

For academics the goals are two-fold; to save on time spent teaching the same objectives at residential school; and to provide ongoing advice and support to students during their RAL use compared to one-off restrictive opportunity during the residential school.

The aim for the faculty is to create more RAL activities for use within the Faculty of Engineering and Surveying, and to better utilise available software licensing.

\section{B. Faculty of Science (Nursing)}

An example of a non-technical activity involves creating an environment of broader impact of RAL activities. Within the Faculty of Science's department of Nursing, prior to using the RAL system, students attend an oncampus laboratory session, to practice preparing an infusion pump used for intravenous drips for use on a patient.

This involved preparing the machine and priming the line that will deliver medication. In addition to equipment manipulation, clinical reasoning practice takes place surrounding decisions and calculations of which medications to deliver using information from a range of situations provided about the test. Under normal laboratory session situation, typical issues of limited access to the equipment, and a lack of quality time-on task cast doubt as to the effectiveness of the existing sessions.

This activity is, in part, a drill of the procedures necessitated for preparing the pump dosage rates and line priming for delivering medication, but it is also a problem-based form of laboratory learning, as the clinical reasoning practice takes place in reference to an authentic hospital situation that informs the laboratory from information about the test patient from which students must then make clinical decisions about suitable medications to administer and the necessary dosage rates.

With the instigation of a RAL variant of this laboratory, following the on-campus laboratory session, students can $\log$ in to RAL system to continue practicing configuring pump and making further clinical decisions and calculations about medications as an extension to the traditional laboratory.

At the student experience level, the laboratory aims to provide additional opportunities for independent practice of professional skills. These are offered in addition to existing activities within the real laboratory setting using the actual physical infusion pumps and associated apparatus.

The aims at a teaching level are to improve overall teaching effectiveness due to a greater diversity of complementary activities being presented to the students for practicing the necessary clinical and practical skills; and to make a variety of RAL activities available which match and support students' practicum experience.

At a faculty level the aim of using the RAL systems is to help the faculty move towards fully online/distance education delivery in all subjects.

TABLE I.

AIMS OF RAL DEVELOPMENTS BY FACULTY AND ORGANISATIONAL LEVEL

\begin{tabular}{|c|c|c|c|c|}
\hline $\begin{array}{l}\text { Aims of } \\
\text { RAL }\end{array}$ & $\begin{array}{l}\text { Faculty of Education - } \\
\text { Robot RAL-ly }\end{array}$ & $\begin{array}{c}\text { Faculty of Education - Grad Dip } \\
\text { Assignment }\end{array}$ & $\begin{array}{c}\text { Faculty of Engineering and } \\
\text { Surveying }\end{array}$ & Faculty of Science (Nursing) \\
\hline $\begin{array}{l}\text { Student } \\
\text { level }\end{array}$ & $\begin{array}{l}\text { To create an exemplar } \\
\text { for student teachers of } \\
\text { how to utilize technolo- } \\
\text { gy in their teaching, and } \\
\text { how to use pedagogies } \\
\text { which enhance chil- } \\
\text { dren's engagement with } \\
\text { technology }\end{array}$ & $\begin{array}{l}\text { To create an assessment task in } \\
\text { which student teachers integrate } \\
\text { technology use, inquiry-based } \\
\text { pedagogy and multiple-KLA cur- } \\
\text { ricular objectives in an instance } \\
\text { of lesson planning }\end{array}$ & $\begin{array}{l}\text { To provide students with } \\
\text { access to expensive and re- } \\
\text { stricted software that they } \\
\text { will need to know how to } \\
\text { use in professional practice } \\
\text { To reduce the need for } \\
\text { students to visit for residen- } \\
\text { tial school }\end{array}$ & $\begin{array}{l}\text { To provide extra opportu- } \\
\text { nities for independent } \\
\text { practice of professional } \\
\text { skills, in addition to exist- } \\
\text { ing necessary activities in } \\
\text { a real lab setting (for ex- } \\
\text { ample, with an infusion } \\
\text { pump present) }\end{array}$ \\
\hline $\begin{array}{l}\text { Teaching } \\
\text { level }\end{array}$ & $\begin{array}{l}\text { To create an exemplar } \\
\text { activity for other aca- } \\
\text { demic staff of how to } \\
\text { enact "pedagogies of } \\
\text { engagement" and utilize } \\
\text { technology within } \\
\text { teaching activities for } \\
\text { teacher education }\end{array}$ & $\begin{array}{l}\text { To create an opportunity for } \\
\text { practicing curricular/pedagogical/ } \\
\text { technological integration that the } \\
\text { Grad Dip program doesn't oth- } \\
\text { erwise allow for }\end{array}$ & $\begin{array}{l}\text { To save on time spent } \\
\text { teaching the same objec- } \\
\text { tives at residential school } \\
\text { To provide ongoing advice } \\
\text { and support to students dur- } \\
\text { ing their RAL use (com- } \\
\text { pared to one-off chance at } \\
\text { residential school) }\end{array}$ & $\begin{array}{l}\text { To improve overall } \\
\text { teaching due to a greater } \\
\text { diversity of complemen- } \\
\text { tary activities available to } \\
\text { students for practicing the } \\
\text { necessary skills } \\
\text { To make a variety of RAL } \\
\text { activities available which } \\
\text { match and support stu- } \\
\text { dents' practicum experi- } \\
\text { ence }\end{array}$ \\
\hline $\begin{array}{l}\text { Faculty } \\
\text { level }\end{array}$ & $\begin{array}{l}\text { - As a basis for "peda- } \\
\text { gogical conversations" } \\
\text { about using RAL in } \\
\text { Faculty's pedagogical } \\
\text { "toolkits" }\end{array}$ & $\begin{array}{l}\text { To accumulate a range of } \\
\text { examples of educational activi- } \\
\text { ties using an inquiry-based peda- } \\
\text { gogical approach }\end{array}$ & $\begin{array}{l}\text { To create more RAL } \\
\text { activities for use within the } \\
\text { Faculty of Engineering and } \\
\text { Surveying }\end{array}$ & $\begin{array}{l}\text { To use RAL systems to } \\
\text { help the Faculty move } \\
\text { towards distance educa- } \\
\text { tion only in all subjects }\end{array}$ \\
\hline $\begin{array}{c}\text { Cross- } \\
\text { faculty/ } \\
\text { institutional } \\
\text { level }\end{array}$ & \multicolumn{4}{|c|}{$\begin{array}{l}\text { - To share knowledge of and experience with online learning tools which improve equity of access to diverse and engaging learning } \\
\text { activities } \\
\text { To provide an example of how the concept of laboratory learning using RALs can be broadened, to inform the development of } \\
\text { similar teaching activities in other faculties } \\
\text { - To extend the use of RAL technologies across the university }\end{array}$} \\
\hline
\end{tabular}




\section{Faculty of Education (Robot RAL-ly)}

This is another instance of a non-technical example that whilst using technology, aims to address broader educational paradigms.

Within this activity small teams of primary school children are tasked with designing and building a track for a specific mobile robot to race along. This is done collaboratively and initially proximally where students had access to the track, and robots directly. Once the tracks are complete, the teams swap tracks and test their design by controlling the robots remotely using the RAL system.

The teachers' task is to direct and guide students during the activity towards a set of educational objectives concerning the principles which govern good design of the racetracks, taking into account the materials provided, robot capabilities and the dynamic performance when being raced. Details of this activity are discussed in [21]. The same activity was repeated with international cohorts [22].

The nature of the laboratory learning in this example is enquiry-based in which students explore the necessary variables in order to make and test predictions so as to be able to draw conclusions within the context.

At a student level the aims are to create an exemplar for pre-service student teachers of how to utilise technology in their teaching, and how to use pedagogies that enhance children's engagement with modern technology.

At a teaching level the aim is to create an exemplar activity for other academic staff of how to enact "pedagogies of engagement" and utilise modern technology within teaching activities for teacher education, as opposed to student education.

At the Faculty level the aim is to use this activity as a basis for "pedagogical conversations" about using RAL in Faculty's pedagogical "toolkits", and extending the concept of what RAL is and can offer.

\section{Faculty of Education (Grad Dip Assignment)}

Following on from the previous case, student-teachers enrolled in a Graduate Diploma in the Faculty of Education view the Robot RAL-ly example, and are then required to conceive of another RAL task or experiment which could form the basis of a planned lesson for high school students. Lessons should be designed to integrate an inquiry-based pedagogy and learning objectives from at least two Key Learning Areas (KLAs or subjects) including technology use within the classroom. Student-teachers were required to also consider how this activity could be 'pitched' to the principal of a school as a worthwhile educational activity, thus further strengthening the value of the activity.

This particular case is a conceptual laboratory only, in which the student-teachers explore the fundamentals of inquiry-based pedagogy and curricular integration where the RAL system merely forms the context of the activity but is not actually used as part of delivering the learning activity.

The aim at the student level is to create an assessment task in which student-teachers integrate technology use within the classroom, including inquiry-based pedagogy and multiple-KLA curricular objectives in an instance of lesson planning.
At the teaching level, the aim is to create an opportunity for practicing curricular; pedagogical; and technological integration that this Graduate Diploma program doesn't presently allow for. At the faculty level, the aim is to accumulate a range of examples of educational activities using an inquiry-based pedagogical approach.

\section{E. Cross-Faculty/Institutional Aims}

At an institutional level the broad aims of undertaking RAL activities exhibit a strong focus on educational goals in alignment with the broad sector strategies. These aims include; to share knowledge of, and experience with, online learning tools that dramatically improve equity of access to diverse and engaging learning activities; to provide an example of how the concept of laboratory learning using RALs can be broadened, to inform the development of similar teaching activities in other faculties; and to extend the use of RAL technologies across the university and inform models of cross-institutional expansion.

All of these aims align with typical institutional values of improving access, and the removal of barriers to engagement and providing effective educational pathways.

\section{INSTITUATIONAL BACKGROUND}

The University of Southern Queensland is a regional distance education provider. About $76 \%$ of students in the Faculty of Engineering and Surveying are located offcampus and study via distance education. In this context providing students with remote access to laboratory equipment will directly improve the learning experience of external students. Prior to the deployment of RAL, students had to rely entirely on residential schools to develop their practical skills. The integration of RAL activities into courses, particularly when used to develop fundament skills and thereby ensure all students are at a similar level of competency, allows more effective and efficient use of time at these residential schools.

Since 2007 the Faculty of Engineering and Surveying has investigated RAL as a concept and driven the development of a system that seamlessly integrates with the Learning Management System (LMS) Moodle. Examples of systems that integrate LMSs and RALs also exist in other projects [23].

USQ is a medium-sized regional Australian university that has a strong history of providing high-quality flexibly distance education. USQ's stated vision is "to be recognised as a world leader in open and flexible higher education", and part of its mission is to "enable broad participation in higher education". To achieve these aims and maintain its status at the vanguard of digital and online learning, USQ recently has made a concerted effort to streamline, expand and enrich student experience through three key initiatives.

The first is an effort to ensure distance students have an equivalent campus experience to full-time face-to-face students. RAL aligns precisely with this initiative. The second is through enhanced infrastructure to support flexible distance education. RAL also is in accord with this strategic direction. The third is through an initiative known as the Digital Futures project. This project is supported through the Australian Government's Collaborative Research Network (CRN) program. RAL is also in harmony with this enterprise since the CRN program is 
designed to build research capacity and one of its key themes is 'technology rich learning environments'.

Further, since the capacity building research agenda will involve encouragement of cross-Faculty and interUniversity engagement and collaboration, RAL has already provided a successful focal point to facilitate informal partnerships in this regard.

Funding through the CRN has allowed the RAL group to build research capacity through the recruitment of a full time postdoctoral research assistant and the provision of two full time research scholarships for $\mathrm{PhD}$ students.

These initiatives are recognised in the recently adopted USQ strategic plan 2013-2015 in which 'Personalised Learning' is stated as one of the key themes. The notion is to establish a learning partnership with students regardless of their background, geographic location, or stage in life. For pedagogical and professional accreditation reasons, practical experiments and laboratory exercises form an integral part of programs in the Faculty of Engineering and Surveying.

To provide external students with practical learning experience equivalent to that of their on-campus peers is logistically difficult and resource intensive since it relies on external students attending several concentrated sessions of laboratory work at on-campus residential schools. One benefit of RAL is to provide FoES (and other Faculty) students with off-site access to practical and laboratory experiments from their home base regardless of geographic location. RAL's facilitation of this enhanced student access clearly aligns with the personalised learning theme of USQ's strategic plan.

In the strategic plan, this theme then cascades into several strategies including the notions of 'accessibility', 'innovative teaching' and 'customisation'. The provision of remote access to video-supported laboratory experimentation bridges the gap between real-life and virtual learning spaces. This allows students, regardless of location, to actively engage in contextual action-oriented learning and achieve course objectives with less emphasis on attending on-campus training sessions.

Therefore RAL significantly increases accessibility for students in accordance with USQ's stated strategic direction. This benefits students by: increasing flexibility of program delivery, providing a more cost and time effective service, enhancing the connection between practical and theoretical knowledge, and increasing availability of laboratory equipment.

This approach clearly reflects innovative teaching practice and allows students to customise their learning activities and conduct practical exercises as they feel they need them. The future development and improvement of the RAL initiative will help to guarantee parity of student experience, regardless of geographic location, and enhance USQ's ability to meet the flexible learning agenda and remain at the vanguard of distance education.

Of course, RAL has broader strategic significance that enrolled students. RAL also provides a strong platform for engagement with stakeholders such as, other Universities, the TAFE and VET sector, local and remote schools, industry, and the general community.

To further encourage the strategic use of RAL and to foster cross-Faculty and inter-University engagement and collaboration, the Associate Deans from the five Faculties have formed an active community of practice. This allows them to work together in empowering staff to design, develop and deliver quality learning experiences for students [24]. This institutional wide approach to supporting staff and students proved invaluable in providing avenues to engage staff from other disciplines and Faculties in RAL activities and ensuring alignment with institutional goals. Hine et al. [25] also stress the importance of strong institutional support for the success of RAL projects.

\section{Methodology}

The aim of the evaluation in this project was to establish the success of the RAL learning activity implementations discussed above. A Program Logic Approach [7] is used to map inputs, activities, outputs, outcomes and impacts. Figure 1 summaries the logic of the program as it was envisaged by staff [20].

The situation is depicted on the left hand side and includes a high percentage of remote students, the reported RAL affordances. Inputs include the curriculum design, study materials for students, IT support, as well as software and hardware that are part of the experiments. Outputs include learning modules that have been developed, students that have been reached, and the staff and third parties that are involved with RAL projects.

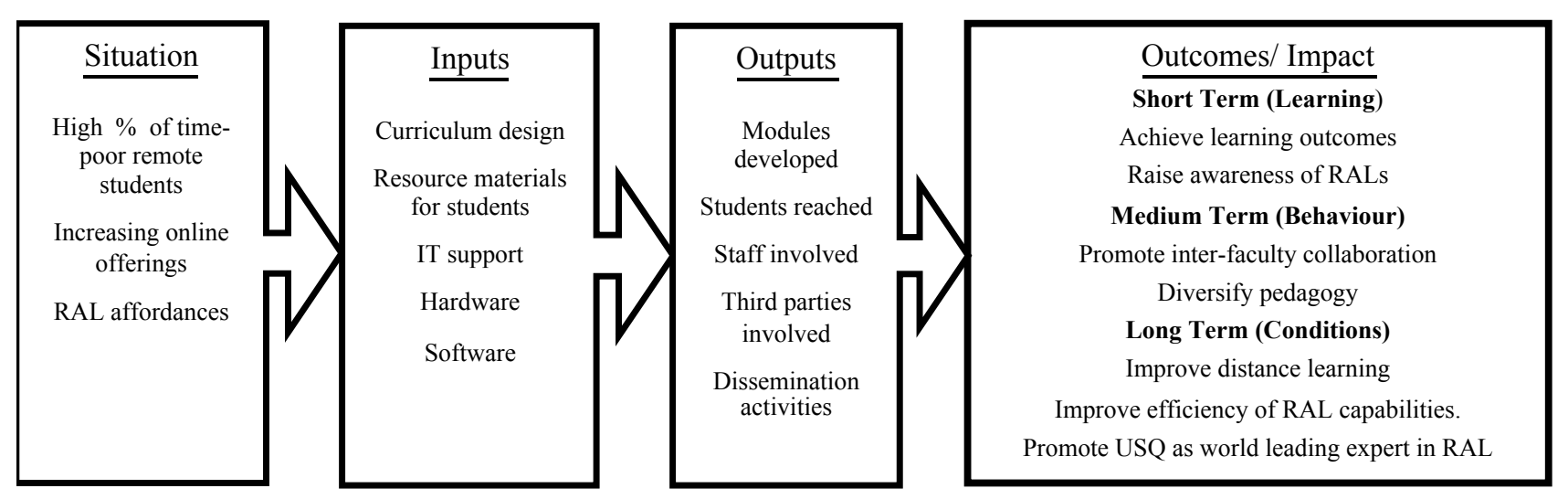

Figure 1. Program logic of RAL implementation [18] 
Dissemination activities and publications are also part of the outputs. The impact is summarised on the righthand side and can be divided into the short-term impact on learning, midterm impact of behaviour and long term impact on conditions. These impacts include achieved learning outcomes for students and raised awareness of RAL; promoting inter-faculty collaboration and diversifying pedagogies; and improving distance learning and the efficiency of RAL capabilities, respectively.

Evaluation questions were formulated surrounding the key areas of appropriateness, effectiveness, impact, efficiency and sustainability [8]. To address these questions, comprehensive data about the learning activities was collected. This included interviews with staff members (10 hours), student focus groups (3 hours in three faculties), observations of classes ( 2 hours), a staff activity diary and analysis of student work. Throughout the evaluation, the implementation teams were consulted as some of the activities were still being developed. This also had the positive side effect that activities were evaluated at different stages in the implementation cycle.

\section{Results against EVALUATION QUESTIONS}

This section summarises results in regards to the evaluation questions.

\section{A. Appropriateness/authenticity}

There is a natural tendency for people to think of activities that are most like traditional laboratories (hands-on manipulation of equipment), when beginning to design RALs. In Engineering and Science faculties at USQ and elsewhere, RALs may consist solely of internet-controlled cameras pointed at physical experiments. A first step away from this model is provided by the spatial science course discussed here. The learning in that course focussed on the use of electronic systems (GIS) to accomplish surveying tasks so the use of computers to facilitate the activity remotely was not a big change from the traditional format of the course. What made it successful was the scenariobased approach taken where the tasks to be performed were clearly linked to professional and learning outcomes. Well-structured support materials also allowed students to interact with the RAL with the minimum frustration.

The other cases had some component of the manipulation of hardware but in each case it was the higher order thinking that such manipulation provoked that was the focus of learning. In education, the use of the Robot RALly directly as a school learning experience (a laboratory at a distance) replicates the laboratory model and is fairly unproblematic. It is interesting that the attempt to get student teachers to use the Robot RAL-ly as a mindtool for thinking about building curriculum appears to have been less successful.

In our estimation this reveals the difficulties inherent in thinking about RALs with the broader definition we have suggested. It was not clear to the student teachers what they had to do with the Robot RAL-ly example suggesting that more scaffolding of their learning experience was necessary. In addition, their organisation of the project within their teams militated against collaborative use of the RAL and thus undermined its efficacy. The fact that some teams appeared to have used the RAL effectively, however, indicates that its impact could be maximised through attention to course design.
In Nursing the procedure of setting up the IV Pump is clearly conceived of as a tool to think about patient care by both students and staff. Staff has planned to develop scenarios and script concordance tests to support the RAL and its use in the course. The reality/authenticity that such supports would deliver is clearly important to students and is likely to be vital to the success of the RAL. As the student discussion showed, it may have been better in this case to develop a simulation which captured the reality of the task rather than delay in order to use particular RAL technologies. A subsequent research project has taken this feedback on-board and has developed and evaluated an IV pump driver emulator [26].

RAL activities lend themselves to learning activities that involve direct manipulation of equipment. Information can either be processed as part of the RAL activity or it can be carried out externally. Scenario-based activities that relate to professional practice in the field also offer opportunities to develop RAL learning activities.

Courses that are organised so that every student must interact with the RAL, individually or collaboratively also offer great opportunities for the inclusion of RAL-based learning activities. Learning occurring through other methods as simulation or as a faux-situation may affect situated learning and assessment [27].

\section{B. Effectiveness}

Delays in implementing RALs made it hard to evaluate their immediate impact in fostering learning, although there are some suggestive indications here about what needs to be done. As noted several times, the ability of RALs to foster learning is not inherent in the tool, but depends on good pedagogical design. In the engineering case study the course and all of its materials was redesigned around the RAL and ample learning support was provided. Students reported themselves satisfied with the learning experience and outcomes. In Nursing, students could clearly see how a RAL would give them the flexibility to be self-directed and self-paced but they also noted that once away from campus it is hard for busy people to find time to spend on their studies. Once again, welldesigned and well-paced courses are key to supporting students in this endeavour.

The Education case study was the only one to address the issue of collaboration and here we see mixed results. The primary school users of the Robot RAL-ly commented that they enjoyed the teamwork, especially when it involved Japan-Australia communications [22]. The student teachers using the RAL for curriculum design purposes did less well in this regard. As with the nurses, they are likely to be busy people who, when working in teams, divide the work up strategically to reduce the time each person contributes. Insofar as course design allows this there can be no expectation that collaborative building of meaning and understanding will occur and hence one of the important affordances of the RAL will be lost.

RAL activities can enhance student-directed, self-paced learning can be enhanced by the ability to access the RAL multiple times as needed. However, it is important that students are prompted to do the RAL activities by suitable activities designed into the course around RAL. Collaboration only happens in RALs when it is built into the activity or builds on everyone's experience of the RAL. 


\section{Impacts}

Limited implementation in our case study examples make it hard to give a measure of student response to these RALs but there is some information from other implementations in Engineering and the discussion with nursing students which allow us to draw some broad conclusions.

Firstly, while students see the use of RALs for practicing their skills at their own time and pace, it can be expected that they will be impatient of glitches in the system that make free interaction with it and pursuit of their intended learning difficult. Where such glitches have been ironed out well in advance and adequate training and support materials were provided, as in the spatial science course, students appreciated the advantages of the RAL.

There are two major barriers to implementation of RALs. The first is the time and effort needed to do the necessary course redesign to include RALs in existing course or build new courses around them. As the spatial science example showed, even in a course which was always heavily electronic in nature, rewriting took 48 hours. Many courses would expect to take longer than this. In addition, for courses that lie outside the engineering faculty, where the technical expertise resides, just getting the appropriate technical support was often a major hurdle and led to delays in implementation or compromises on what was possible.

However, the second barrier is perhaps more consequential. Using a RAL, in most cases, is not just going to be a matter of re-writing something that already exist for remote access. It will require rethinking of the learning task within the kind of definition of laboratory that we have provided above, and then a course design that makes best use of that experience to reach the desired learning outcomes. This suggests that more attention needs to be paid to the principles of constructive alignment and that this may call for some staff training whether in formal settings such as Postgraduate Certificates in Higher Education courses, or through local initiatives of the Learning and Teaching Support Unit. Technical and training support will be central to further uptake of RALs across the university.

Students are in principle in favour of RALs where they clearly address the goals and learning objectives of the course. However, students are impatient of unresponsive or opaque technology and unauthentic RALs; i.e. activities that do not offer educational benefits. Staff needs considerable time to design good RALs and integrate them into courses appropriately. It is also essential for staff that timely and focused technological support is provided. The University can encourage RAL use by providing the appropriate support to staff in their development

\section{Efficiency}

As reflected in all cases, there is considerable investment required to mount a RAL in a course. The laboratory itself must be created, which may or may not entail the use of specialized equipment. Even if the practice equipment already exists as in the nursing case, it must be set up for remote manipulation and the links and control must be maintained in good working order. All RALs, whether they involve equipment or not, will require support materials in the shape of scenario, source materials, instructions and so on, as well as clear instructions about how learning should proceed and how to operate the RAL. All of this takes time to create, review and update. Special training may also be necessary as already discussed.

On the other hand, if the RAL can replace aspects of the course normally requiring attendance at a residential school, as in the spatial science course, there can be large savings for both students and staff. The comments of the nursing students about the need for RALs to augment and not replace campus classes raises some concerns about how often this kind of saving will be practicable.

There may be savings to be had by sharing RALs with other universities or schools. This currently happens with respect to the remote laboratories in engineering though Labshare (http://www.labshare.edu.au/). The EU-funded LiLa Project (http://www.lila-project.org) is another which provides example laboratories and organisational resources but applies only to science and engineering.

Key cost factors include the development of laboratories. Resources are necessary for physical as well as conceptual laboratories. Costs are encountered to develop appropriate learning and support materials; and to train staff where necessary. Savings are possible if for appropriate courses RALs replace residential school attendance.

This has already occurred in the discipline of Surveying, but is more problematic in engineering discipline as attendance at residential school is a requirement of the accreditation body, Engineers Australia. Sharing lab materials/design/access with other institutions will create savings where the other institutions provide similar labs in return.

\section{E. Sustainability}

As noted above the ways in which the university might maintain and extend the use of RALs relate to providing adequate technical support, in the shape of the provision and maintenance of hardware, control systems and ongoing ICT support, and pedagogical support in providing time with the staff and resources to develop suitable learning materials and design courses, and the training to do so effectively where necessary.

In order to achieve rational outcomes it will probably be necessary to articulate a policy for the University with respect to the promulgation of RALs. Such a policy should aid decision making with respect to:

- Identifying nature and scope of university commitment to RALs

- Establishing working parties/committees to promote RALs

\section{- Allocating funding}

Such policy would also benefit from paying attention to issues of IT learning platforms and other technological matters. Ease and transparency of use is vital for the success of a RAL. Not only do technological issues irritate staff and students, they are expensive and timeconsuming. Care therefore needs to be taken in the selection of technologies to be employed in RALs. Students can nowadays be assumed to be fluent in any web-based computing application so technological developments need to stay close to this model. Any changes to the Learning Management System need to take account of the interface with RALs.

If RAL approaches are to be promoted throughout the university, staff will need help in identifying what courses 
and activities lend themselves or could be adapted to RALs. Although the project was unable to garner any interest from either the Arts of Business faculties for this project it seems likely that opportunities exist there to introduce RALs and deliver the learning benefits they offer - flexible, active and collaborative learning.

To ensure the sustainability of the RAL development, policies should be developed to guide decision-making. A survey of potential RAL activities across all faculties should be undertaken. Staff need adequate technological support and training in course design for RALs. Changes to the LMS need to be taken into account to support the need to interface with RALs.

\section{FINDINGS}

The evaluation showed that RAL activities can have a great impact on student learning. However, it is important that the activities are well embedded within the other learning materials. Scaffolded learning materials that support the activity are also important. RAL learning activities should not be treated any differently from other learning tools. From an educational perspective this means that design and delivery of learning activities is the most important aspects and the principles of constructive alignment should guide the development of learning activities. Intended and achieved learning outcomes are the key motivator and ultimate measure of success of a learning activity.

The traditional definitions of RAL systems as hardware control mechanisms is limiting and extending the definition allows for a much wider use of these learning tools. Taking this project's broader conception of what can constitute a laboratory learning experience allows for greater flexibility in understanding the potential for wider application of RAL. The actual activities engaged in by students may involve: investigation of ideas, concepts or facts, modelling with data, experimentation with creating certain outcomes by manipulating variables, or the creation of a solution or range of solutions to a relevant problem or scenario.

\section{THE PATH FOWARD}

At present the overall RAL system at USQ is stable and useable. Of consideration now is how the outcomes and findings from this study will direct the strategic direction for RAL and its implementation as a teaching tool across the wider university community.

The outcome of the RAL project was very much dependant on its initial remit as a learning and teaching tool. Initial implementations and testing of the RAL system focussed on the "access" part or system paradigm of RAL. With the benefit of having RAL operational for a number of years, this has allowed questions regarding the learning potential to be discussed and evaluated.

New RAL learning activity would benefit from a pedagogic-first approach, than an access and delivery first model. This would mean that close integration with the learning objectives are realised for each designed activity, as well as the integration of the system as a whole. For individual learning activities the authenticity of the experiment is important. This describes the manner of its design to describe solid physical artefacts that are believable as real world experiences.
Whilst at present RAL technologies may not be able to replace residential schools or on campus practical experimentation due to specific requirements of accreditation for engineers within Australia, there is capacity for RAL to be used for preparatory classes alongside simulations, in order to achieve an authentic experience on which students can build in real experimental situations.

Of immediate importance is the continuing research into the effects and affects of RAL on relevant student cohorts. Optimising development methods for delivery are important, but so too is the perceptions of RALs use and the discovery of how real the experiment needs to be before sufficient believability is achieved.

Integrating RAL into several individual courses has allowed examiners to look more critically at the learning objectives of the course in general and the learning objectives of laboratory sessions in particular. This has led the faculty to recognise that, as our knowledge of RAL matures, a major consideration in the near future will be to strategically plan the further implementation of RAL into the curriculum at the program level.

At this level key questions revolve around how to use RAL most effectively and efficiently. Decisions need to be made as to which courses would benefit most from the introduction of RAL activities. These types of decisions need to continue our current focus on student benefits and learning outcomes, while at the same time consider the financial implications (this is most often through a cost/benefit analysis). Demonstrating how RAL can effectively inculcate the requisite graduate competencies and ultimately help students achieve necessary threshold learning outcomes is becoming vitally important to professional registration bodies such as Engineers Australia as well as university accreditation bodies.

To effectively plan the integration of RAL at an overall program level will require a systematic review of the program structure, review of existing laboratory and practical activities (whether RAL or not), mapping of activities against requisite graduate outcomes, skills and competencies, and finally the rationalisation of this information into a framework for future RAL adoption that can be used by other programs and Faculties.

Once the plan is agreed, the operational imperatives can be identified. For example, it may be decided to focus immediate attention on priority areas such as large classes or courses where problems have been identified (though student feedback and retention rates) with students' understanding of fundamental underlying concepts.

\section{CONClusions}

The results section has summarised key issues in the context of moving RALs from individual activities to a comprehensive, institutional system which can be used in many disciplines. Some barriers in this context are generic and apply to other technologies in the context of learning and teaching as well [28]. Other key issues relate to pedagogical considerations and the purpose RAL activities have in the curriculum. For any RAL learning activity it is important that it is well integrated into the course design and delivery. Developing RAL learning activities cannot be considered as a cost saving measure. Implementing activities not only requires hardware and software but also the development of comprehensive and integrated learning materials. The quality of a RAL learning activity 
largely depends on the quality and supporting role of the learning materials.

\section{ACKNOWLEDGMENT}

The authors would like to thank the various academics, laboratory managers and students who participated in this study. This work has been funded by a USQ LTPF grant. The authors would also like to thank Lesley Jolly, Strategic Partnerships, for their assistance with the evaluations that were undertaken as part of this project.

\section{REFERENCES}

[1] J. Ma and J. Nickerson, V., "Hands-On, Simualted and Remote Laboratories: A Comparative Literature Review," $A C M$ Computing Surveys, vol. 38, pp. 1-24, 2006. http://dx.doi.org/10.1145/1132960.1132961

[2] A. A. Kist and P. Gibbings, "Inception and management of remote access laboratory projects," presented at the AaeE 2010: 21st Annual Conference of the Australasian Association for Engineering Education, Sydney, Australia, 2010.

[3] L. Bowtell, C. Moloney, A. A. Kist, V. Parker, A. Maxwell, and N. Reedy, "Using remote access laboratories in nursing education," presented at the 9th International Conference on Remote Engineering and Virtual Instrumentation (REV 2012), Bilbao, Spain, http://dx.doi.org/10.1109/REV.2012.6293148

[4] P. Orduna, J. Garcia-Zubia, J. Irurzun, D. Lopez-de-Ipina, and L. Rodriguez-Gil, "Enabling mobile access to Remote Laboratories," in Global Engineering Education Conference (EDUCON), 2011 IEEE, 2011, pp. 312-318. http://dx.doi.org/10.1109/EDUCON. 2011.5773154

[5] V. J. Harward, J. A. del Alamo, S. R. Lerman, P. H. Bailey, J. Carpenter, K. DeLong, C. Felknor, J. Hardison, B. Harrison, I. Jabbour, P. D. Long, M. Tingting, L. Naamani, J. Northridge, M. Schulz, D. Talavera, C. Varadharajan, W. Shaomin, K. Yehia, R. Zbib, and D. Zych, "The iLab Shared Architecture: A Web Services Infrastructure to Build Communities of Internet Accessible Laboratories," Proceedings of the IEEE, vol. 96, pp. 931-950, 2008. http://dx.doi.org/10.1109/JPROC.2008.921607

[6] D. Lowe, S. Murray, L. Weber, M. De la Villefromoy, A. Johnston, E. Lindsay, W. Nageswara, and A. Nafalsk, "LabShare: Towards a National Approach to Laboratory Sharing," in 20th Annual Conference of the Australasian Association for Engineering Education (AaeE), University of Adelaide, 2009.

[7] E. Taylor-Powell, L. Jones, and E. Henert. (2003). Enhancing Program Performance with Logic Models, University of Wisconsin-Extension, Feb. 2003. Available: http://www.uwex.edu/ ces/pdande/evaluation/evallogicmodel.html

[8] A. A. Kist, P. Gibbings, and A. Maxwell, "From Individual Remote Access Laboratory Implementations to Institutional Learning Tools," presented at the IEEE EDUCON2013, Berlin, Germany, 2013.

[9] A. A. Kist, A. Maxwell, and P. Gibbings, "Expanding the Concept of Remote Access Laboratories " presented at the 119th ASEE Annual Conference and Exposition, San Antonio, Texas, 2012.

[10] G. V. Kondraske, R. A. Volz, D. H. Johnson, D. Tesar, J. C. Trinkle, and C. R. Price, "Network-based infrastructure for distributed remote operations and robotics research," Robotics and Automation, IEEE Transactions on, vol. 9, pp. 702-704, 1993. http://dx.doi.org/10.1109/70.258062

[11] B. Aktan, C. A. Bohus, L. A. Crowl, and M. H. Shor, "Distance learning applied to control engineering laboratories," Education, IEEE Transactions on, vol. 39, pp. 320-326, 1996. http://dx.doi.org/10.1109/13.538754

[12] E. Lindsay, "The Impact of Remote and Virtual Access to Hardware upon the Learning Outcomes of Undergraduate Engineering Laboratory Classes," $\mathrm{PhD} \mathrm{PhD}$, Department of
Mechanical and Manufacturing Engineering, The University of Melbourne, Melbourne, 2005.

[13] J. Trevelyan, "Lessons Learned from 10 Years Experience with Remote Laboratories," in International Conference on Engineering Education and Research, VŠB-TUO, Ostrava, 2004, pp. 687-697.

[14] L. D. Feisel and A. J. Rosa, "The Role of the Laboratory in Undergraduate Engineering Education," vol. 94, pp. 121-130, 2005.

[15] F. Arango, C. Chang, S. Esche, K., and C. Chassapis, "A Scenario for Collaborative Learning in Virtual Engineering Laboratories," in 37th ASEE/ISEE Frontiers in Education Conference, Milwaukee, WI, 2007, pp. F3G-7 - F3G-12.

[16] B. Hanson, P. Culmer, J. Gallagher, K. Page, E. Read, A. Weightman, and M. Levesley, "Remote laboratories in the curriculum," presented at the 11th IASTED International Conference Computers and Advanced Technology in Education., 2008.

[17] R. T. White, "The link between the laboratory and learning," International Journal of Science Education, vol. 18, pp. 761 - 774, 1996. http://dx.doi.org/10.1080/0950069960180703

[18] M. Ally, "Foundations of Educational Theory for Online Learning " in Theory and Practice of Online Learning, T. Anderson and F. Elloum, Eds., ed: Athabasca University, 2004, pp. 3-31.

[19] B. Mergel. (1998). Instructional Design \& Learning Theory. Available: http://www.usask.ca/education/coursework/802papers/ mergel/brenda.htm

[20] A. A. Kist, "Barriers to Adopting Remote Access Laboratory Learning Activities," presented at the AaeE 2012: 23st Annual Conference of the Australasian Association for Engineering Education, Melbourne, Australia, 2012.

[21] A. A. Kist, A. Maxwell, P. Gibbings, R. Fogarty, W. Midgley, and K. Noble, "Engineering for primary school children: Learning with robots in a remote access laboratory," presented at the 1st World Engineering Education Flash Week, SEFI Annual Conference (European Society for Engineering Education), Lisbon, 2011.

[22] A. Maxwell, R. Fogarty, P. Gibbings, K. Noble, A. A. Kist, and W. Midgley, "Robot RAL-ly International - Promoting STEM in elementary school across international boundaries using remote access technology," presented at the REV2013 Sydney, Australia, 2012.

[23] M. C. C. Lobo, G. R. Alves, M. A. Marques, C. Viegas, R. G. Barral, R. J. Couto, F. L. Jacob, C. A. Ramos, G. M. Vilao, D. S. Covita, J. Alves, P. S. Guimaraes, and I. Gustavsson, "Using remote experimentation in a large undergraduate course: Initial findings," in Frontiers in Education Conference (FIE), 2011, 2011, pp. S4G-1-S4G-7.

[24] K. Noble, L. J, B. L, S. J, and P. Gibbings, "An Associate Deans' Community of Practice: Rising to the local leadership challenge to enhance learning and teaching quality," DeHub Quarterly, vol. 7, 2011.

[25] Nicolas Hine, G. R. Alves, J. M. Ferreira, C. E. Pereira, J. G. Zubia, H.-H. Erbe, O. Herrera, L. Chiang, J. B. M. Alves, L. E. Sucar, and D. Muller, "Institutional Factors Governing the Deployment of. Remote Experiments: Lessons from the REXNET Project," presented at the 4th International Conference on Remote Engineering and Virtual Instrumentation (REV'07), Porto, Portugal, 2007.

[26] L. Bowtell, A. A. Kist, D. Osbourne, and V. Parker, "Interactive Emulator System to Aid Clinical Practice Outcomes for Nurses " International Journal of Online Engineering (iJOE), 2013.

[27] J. J. Cumming and G. S. Maxwell, "Contextualising authentic assessment," Assessment in Education: Principles, Policy \& Practice, vol. 6, pp. 177-194, 1999. http://dx.doi.org/10.1080/ 09695949992865

[28] D. L. Butler and M. Sellbom, "Barriers to Adopting Technology for Teaching and Learning," Educause Quarterly, vol. 25, pp. 22$28,2002$. 


\section{AUTHORS}

Alexander A. Kist is with the Faculty of Engineering and Surveying, University of Southern Queensland, Toowoomba, Australia (kist@ieee.org).

Peter Gibbings is with the Faculty of Engineering and Surveying, University of Southern Queensland, Toowoomba, Australia (peter.gibbings@usq.edu.au ).

Andrew D. Maxwell is with the Faculty of Engineering and Surveying, University of Southern Queensland, Toowoomba, Australia (andrew.maxwell@usq.edu.au ).

Hannah Jolly is with the Faculty of Engineering and Surveying, University of Southern Queensland, Toowoomba, Australia (hannah.jolly@usq.edu.au).

This work was supported in part by a USQ LTPF grant. This article is an extended and modified version of a paper presented at the EDUCON2013 conference held at Technische Universität Berlin, Berlin, Germany from March 13-15, 2013. Received 15 May 2013.Published as resubmitted by the authors 27 May 2013. 